\title{
Autoren dieses Heftes
}

Gerald Becker-Neetz

Alexander Blankenagel

Ingwer Ebsen

Jürgen Frank

Dieter Hart

Andreas Knobelsdorf

Thamas Kreuder

Ulrich Mückenberger

Ulrich K.Preuß

KLaus Sievekung

Gerhard Uebersobn

Gerd Winter

Rainer Wolf geb. 1955; Dr. jur.; Wissenschafrlicher Mitarbeiter am Institur für öffontliches Recht der J. W. Goethe-Universitär, Frankfurt am Main; Senckenberganlage 3I, 6000 Frankfur am Main 1.

geb. 1946; Dr. jur.; Professor für öffentliches Rechr und Ostreche an der Universität Würzburg: Domerschulstr. 16, 8700 Würzburg.

geb. 1943; Dr. jur.; Professor für öffentliches Recht an der Westfälischen Wilhelms-Universität Münster; Universitätsstr. 14-16, 4400 Münster.

geb. 194I; Dr. rer. pol.; Professor für Wircschaftswissenschaft an der Universitäc Hannover, Fachbereich Rechtswissenschaft; Hanomagstr. 8, 3000 Hannover 91 .

geb. 1940; Dr. jur.; Professor für Bürgerliches Rechr und Wirtschaftsrecht an der Universität Bremen; Postfach $33044^{\circ}, 2800$ Bremen.

geb. 1962; stud. jur. an der Universiż̈t Bielefeld; Postfach 2r43, 4830 Gütersloh 1.

geb. 1960; Rechesreferendar; Jordanstr. 15, 6000 Frankfurt am Main 90.

geb. 1944; Dr.jur.; Professor für Arbeitsrecht an der Hochschule für Wirtschaft und Politik in Hamburg; Kreftingscr. 4, 2800 Bremen.

geb. 1939; Dr. jur.; Professor für öffentliches Recht an der Universität Bremen; z. Zr. ZiF, Wellenberg 1, 4800 Bielefeld.

geb. I945; Dr.jur.; Wissenschaftlicher Mitarbeiter am Zentrum für Europäische Rechispolitik (ZERP) der Universität Bremen; Universitätsallee, GW I, 2800 Bremen 33.

geb. 1955; Wissenschaftlicher Mitarbeiter am Institur für öffentliches Recht der J. W. Goeche-Universität Frankfurt am Main; Senckenberganlage 3I, 6000 Frankfurt am Main I.

geb. 1943; Dr.jur.; Professor für öffencliches Recht und Direktor des Zencrums für Europäische Rechrspolirik der Universität Bremen; Universitärsallee, GW I, 2800 Bremen 33.

geb. 1950; Dr. jur.; Oberregierungsrat im Ministerium für Stadrentwicklung, Wohnen und Verkehr des Landes Nordrhein-Westralen; Drakeplatz I, 4000 Düsseldorf. 